\title{
Performance Evaluation and Optimal Design of Supermarket Refrigeration Systems with Supermarket Model "SuperSim", Part I: Model Description and Validation
}

\author{
Y.T. Ge*, S.A. Tassou \\ Mechanical Engineering, School of Engineering and Design, Brunel University, \\ Uxbridge, Middlesex, UB8 3PH, UK
}

\begin{abstract}
Conventional supermarket refrigeration systems are responsible for considerable $\mathrm{CO}_{2}$ emissions due to high energy consumption and large quantities of refrigerant leakage. In the effort to conserve energy and reduce environmental impacts, an efficient design tool for the analysis, evaluation and comparison of the performance of alternative system designs and controls is required. This paper provides a description of the modelling procedure employed in the supermarket simulation model 'SuperSim' for the simulation of the performance of centralised vapour compression refrigeration systems and their interaction with the building envelope and HVAC systems. The model which has been validated against data from a supermarket has been used for the comparison of $\mathrm{R} 404 \mathrm{~A}$ and $\mathrm{CO}_{2}$ refrigeration systems and the optimisation of the performance of transcritical $\mathrm{CO}_{2}$ systems. These results are presented in Part II of the paper.
\end{abstract}

Key Words: supermarket, refrigeration, energy consumption, modelling, validation..

* Corresponding author. Tel.:+44 1895 266722; fax: +44 1895256392. 
E-mail address:yunting.ge@brunel.ac.uk

\section{Nomenclature}

$\begin{array}{ll}A, B & \text { coefficients } \\ C_{p} & \text { specific heat }\left(\mathrm{J} \mathrm{kg}^{-1} \mathrm{k}^{-1}\right) \\ h & \text { specific enthalpy }\left(\mathrm{J} \mathrm{kg}^{-1}\right) \\ H T & \text { high temperature } \\ L T & \text { low temperature } \\ m & \text { mass flow rate }\left(\mathrm{kg} \mathrm{s}^{-1}\right) \\ N & \text { number } \\ Q & \text { load, cooling capacity }(\mathrm{W}) \\ R & \text { ratio } \\ R H & \text { air relative humidity }(\%) \\ T & \text { temperature }(\mathrm{K}) \\ W & \text { temperature }\left({ }^{\circ} \mathrm{C}\right) \\ W & \text { volumetric flow rate }\left(\mathrm{m}^{3} \mathrm{~s}^{-1}\right) \\ & \text { power }(\mathrm{W})\end{array}$

Greek symbols

$\rho$

density $\left(\mathrm{kg} \mathrm{m}^{-3}\right)$

\section{Subscripts}

$a$

air
A, asw
anti sweat heater
ain
air inlet 


\begin{tabular}{|c|c|}
\hline aout & air outlet \\
\hline case & display cabinet \\
\hline $\mathrm{cd}$ & condenser, condensing \\
\hline$c 01$ & cold room group 01 \\
\hline $\mathrm{c}_{1} \sim \mathrm{c}_{6}$ & coefficients \\
\hline$d 01, d 02,03$ & display cabinet groups 01,02 \\
\hline$D, d e f$ & defrost \\
\hline dew & dew point \\
\hline evfan & evaporator fan \\
\hline fan & fan \\
\hline$f l$ & full load \\
\hline $\inf$ & infiltration \\
\hline onefan & one fan \\
\hline$p l$ & part load \\
\hline$L$, lat & latent \\
\hline light & cabinet light \\
\hline$m$ & minimum \\
\hline$r$ & rated, refrigerant \\
\hline $\mathrm{rcd}$ & refrigerant condensing \\
\hline rin & refrigerant inlet \\
\hline rout & refrigerant outlet \\
\hline sd & saturated discharge \\
\hline sen & sensible \\
\hline$s p$ & specified \\
\hline$s S$ & saturate suction \\
\hline$T$, tot & \\
\hline
\end{tabular}




\section{Introduction}

A modern supermarket requires considerable amounts of electricity and gas for refrigeration, lighting, baking and the maintenance of a comfortable retail environment for the staff and customers. The total electrical energy consumption of grocery stores is approximately $12 \mathrm{TWh}$ and represents approximately $3.5 \%$ of the UK's total electrical energy consumption (Tassou, 2007) More than half of the energy used in a modern supermarket can be attributed to refrigeration systems. Lighting accounts for between $20 \%$ and $25 \%$ and HVAC and ancillary services for the remainder (Tassou and Ge , 2008). The refrigeration system is also charged with a large amount of refrigerant, in the majority of cases HFC, which is directly responsible for significant $\mathrm{CO}_{2}$ emissions due to refrigerant leakage from the system.

To increase the energy efficiency of supermarket refrigeration systems, several advanced technologies can be applied, which include more efficient components such as compressors and heat exchangers, combined heat and power and trigeneration in combination with sorption refrigeration systems, heat recovery, natural refrigerants and advanced control strategies and system integration (Tassou and Ge , 2008). For the evaluation and ultimate implementation of such technologies, simulation with an efficient and reliable system model could be the optimum way to compare an experiment which may be overly expensive and time consuming to be achievable otherwise.

There are currently four supermarket energy simulation software with built-in supermarket refrigeration system models in the open literature which are: “Cybermart" (Arias, 2004) , "EnergyPlus" (EnergyPlus, 2009), "Retscreen” (RETScreen, 2009), and "SuperSim" . In addition, there are two other software for 
supermarket refrigeration systems (van der Sluis, 2004), “Econu Koeling” (Econu Koeling, 2003) and "ORNL Supermarket Spreadsheets" (ORNL, 2003). These, however, do not incorporate the simulation of the building and HVAC systems and will not be considered further in this paper.

The four supermarket energy simulation models universally recognize that the total energy consumption of a supermarket is the summation of the energy consumption of the various major subsystems such as the refrigeration systems, HVAC and the interaction between these subsystems. However, the methods used to predict the energy consumption of each subsystem and the interactions between the subsystems are different. The HVAC energy consumption depends to some extent on the heating and cooling loads of the building envelope. For the building loads, all the supermarket models, with the exception of "Retscreen", employ quasi-steady state modelling techniques and the Heat Balance Method to calculate the heating and cooling loads, albeit with differing modelling complexities. "CyberMart" considers the building to be a singular zone and calculates the heating and cooling loads from the heat balance of the room air, room surfaces and building structure (Dokka, 2001). In "EnergyPlus", the cooling and heating loads are calculated from a comprehensive building simulation model which provides a coupled simulation of building loads, systems and plant. "Retscreen" considers the building as a single zone and calculates the heating and cooling loads in a steady state operation with the use of monthly mean climatic data. "SuperSim" is based on multizone building simulation within TRNSYS (TRNSYS,2005), which is a transient system simulation program with a modular structure.

The HVAC models for each program are commonly based on the operation of air handling plant. Nonetheless, the ventilation and fresh air flow rates are treated differently within each program. In "Cybermart", the fresh air flow is controlled by 
the space air quality whereas in "Retscreen" and "SuperSim" the fresh air quantity is treated as an input to the model. In "EnergyPlus", the ventilation can be controlled by a schedule which can be modified in response to changes in the external and internal environment.

The modern supermarket refrigeration system consists of at least one low temperature (LT) and one medium or high temperature (HT) circuit, depending on the size of the supermarket and the number and type of refrigerated display fixtures used. For each temperature circuit at part-load conditions, the actual total cooling load, power consumption from compressors and fans, and potential heat reclaim from the refrigeration system can be calculated by the aforementioned models using different simulation strategies. The cooling load of the refrigerated display cabinets in the store is depended on the space air conditions of temperature and relative humidity. The temperature is normally controlled to a fixed set-point whereas the relative humidity is allowed to float. The internal space parameters are predicted hourly by "Cybermart", daily by "RetScreen" and dynamically by both "EnergyPlus" and "SuperSim" where the calculation time step can be changed to suit the output requirements. All programmes require the design load of each display cabinet including the power requirements of fans and lights to be specified. "Cybermart" and "RetScreen" require the data at two conditions, $22^{\circ} \mathrm{C}$ and $65 \% \mathrm{RH}$ and $25^{\circ} \mathrm{C}$ and 60\% RH, whereas "SuperSim" and "EnergyPlus" require additional information such as the cabinet length and the temperature at inlet and outlet of the evaporator. "SuperSim" also requires correlations for the total, latent and defrost loads with space humidity to incorporate the influence of relative humidity on the performance of the cabinet.

This paper concentrates on the SuperSim model and its application to the simulation of the energy consumption of supermarket refrigeration systems. The 
paper builds on previous work by the authors and enhancements to the model to speed up hourly system simulations for a whole year (Ge and Tassou, 2000). The original model concentrated on detailed simulation of the compressor, evaporator and condenser coils based on first principles and distributed modelling approaches. Although the original approach was useful in providing a good insight of refrigeration system performance over a short period of time it is not convenient for use to carry out seasonal energy simulations.

For seasonal simulations presented in this paper, a simplified condenser model was used based on the lumped parameter modelling approach. The evaporator model is based on manufacturers' data and correlations that relate the extraction rate (cooling load) of the evaporator to the evaporating temperature, cabinet design product temperature and ambient conditions. The HVAC model is designed with the capability of evaluating the effect of different design options, such as variable fresh air flow rates and heat recovery on the overall system performance. The model was validated against field measurements. Part I of the paper describes the SuperSim model and validation results. In Part II of the paper the model is used to evaluate different design options including a comparison of $\mathrm{R} 404 \mathrm{~A}$ and $\mathrm{CO}_{2}$ refrigeration systems for the test supermarket.

\section{System and model description}

Data from a supermarket in Glasgow in the UK were used in this study. For the purposes of the simulation the supermarket was arranged into 14 zones, as shown in Fig. 1. The temperature of the sales area was controlled with a constant volume air handling unit (AHU) comprising of supply and return air fans, heat reclaim coil (HRC), reheat coil (RHC) and supply and return air ducts and dampers. The AHU 
arrangement is shown in Fig. 2. The system employed heat recovery from the compressor discharge of the refrigeration system to heat the supply air to the sales area which was further reheated by a reheat coil if required to maintain the set point temperature in the sales area. The following sections provide a detailed description of the design and control parameters.

There are interactions between the building, the HVAC and refrigeration systems (Fig. 2). The space air conditions in the sales area can vary in response to a number of variables such as external weather conditions, internal gains including lighting, customers, store schedules and controls for the AHU and refrigeration systems. In the sales area there are heat and mass transfer exchanges between the refrigeration fixtures and the internal environment which influence both the internal conditions and the energy consumption of the refrigeration plant. To account for all the interactions and their impact on energy consumption it is essential that the models of the three main subsystems are integrated into an overall supermarket system model. This integration is shown in Fig. 3.

In Fig. 3 one-directional arrows represent data flows from one sub-model to another, whereas two-directional arrows signify interactions between the subsystems and data flows to and from each submodel.

The modelling approach assumes that the design condition represents full load operation of the refrigeration systems. In the case of this paper, the design condition assumes a $50{ }^{\circ} \mathrm{C}$ condensing temperature for each temperature pack, $-10{ }^{\circ} \mathrm{C}$ evaporating temperature for the $\mathrm{HT}$ pack and $-32^{\circ} \mathrm{C}$ evaporating temperature for the LT packs. The design ambient temperature was taken as $35^{\circ} \mathrm{C}$. For each temperature pack, refrigerant subcooling and superheating were set at $5 \mathrm{~K}$, with a $2 \mathrm{~K}$ saturated temperature equivalent pressure drop was assumed in the suction line of each pack. 


\subsection{Building model}

The building model is based on the TRNSYS multizone building module (TRNSYS,2005). TRNSYS is a transient system simulation program with a modular structure to recognise a system description language whereby the user specifies the components that constitute the system and the manner in which they are connected. As shown in Fig. 1, the floor layout of the supermarket is divided into 14 zones according to their functions and temperature control. The sales area of the supermarket was $4329 \mathrm{~m}^{2}$. For each zone, descriptions of the building fabric such as wall type, size and window details are required in addition to the specification of infiltration, ventilation, cooling and heating, gains, schedules, and temperature and humidity controls for each zone. In addition, inputs to the model are local hourly weather data including ambient temperature, humidity, wind velocity and direction and solar radiation. The schedules refer to the store's daily opening and closing time, the number of customers in each hourly period as well as the pattern of other internal gains. Space cooling was not provided to the store and heating was supplied through the air handling unit. The space temperature was controlled at $20 \pm 1{ }^{\circ} \mathrm{C}$ but the humidity was allowed to float.

\subsection{HVAC model}

The internal space air temperature in the sales area was controlled by an all air system through an AHU, as shown in Fig. 2. To minimize infiltration, the sales area was maintained under positive pressure by returning only $90 \%$ of the supply air to the AHU. The minimum fresh air flow was set at $15 \%$ of supply air. A cascade control method was used to control the supply air temperature. The supply air temperature 
set-point (SATSP) was controlled at $30^{\circ} \mathrm{C}$ when the return air temperature (RAT) was less than $19^{\circ} \mathrm{C}$, to $25^{\circ} \mathrm{C}$ for RAT over $21^{\circ} \mathrm{C}$, and on a linear scale between $30^{\circ} \mathrm{C}$ and $25^{\circ} \mathrm{C}$ with RAT between $19^{\circ} \mathrm{C}$ and $21^{\circ} \mathrm{C}$. The supply air temperature was heated through the refrigeration system heat recovery coil (HRC) and the reheat coil (RHC) in sequence. The two heat exchangers were modelled using the effectiveness-NTU method.

\subsection{Refrigeration system model}

The refrigeration fixtures in the supermarket were served by three multicompressor packs (racks): one HT pack and two LT packs(LT1 and LT2). Each temperature pack served an independent refrigeration circuit consisting of an aircooled condenser and several evaporator coils within various refrigeration fixtures such as display cabinets and cold rooms. Fig. 4 shows a schematic diagram of the HT refrigeration circuit and its interactions with the building and HVAC system. Fig. 5 shows the process on the $\mathrm{P}-\mathrm{h}$ diagram. The refrigerant from each operational compressor flows into the discharge manifold at "2" and then to the heat reclaim coil where it is desuperheated to " $2 \mathrm{a}$ " before entering the condenser. The condensed or subcooled refrigerant then flows into the receiver at " 3 " from where it is distributed to refrigerant fixture groups with similar evaporating temperatures. The evaporator refrigerant inlet and outlet for cabinet group 1 are at "4" and "5" respectively, cabinet group 2 at " 4 "" and " 5 '", and the cold room group 1 at " 4 "” and " 5 "'”. Although only two cabinet groups and one cold room group are shown in the diagram, there were more groups in the actual supermarket. As the refrigerant flows through the suction line its temperature increases and pressure decreases to state point " 6 ", "6" and " 6 "" respectively for the three fixture groups. The arrangement for the LT circuit 
for the frozen food fixtures is similar with that for the chilled temperature circuit but without the heat recovery.

The refrigeration system model should be capable of predicting the hourly and total power consumption of the refrigeration systems for the entire year. To achieve this, the state and properties of the refrigerant at all the main cycle points " 1 ", " 2 ", "2a", "3", "4", "5" and "6" need to be established at each ambient or part load condition.

Furthermore, the full-load and part-load refrigeration loads need to be calculated in order to determine the energy consumption of each refrigeration pack. Using fixed evaporator temperature controls, the evaporating temperature is specified at design conditions. The condensing temperature will be dependent on the control strategy employed for condensing (head pressure) control and can be fixed or allowed to float with ambient temperature.

The models for the calculation of the refrigeration load of each compressor pack and the performance of the compressor and condenser are described below.

\subsubsection{Calculation of the refrigeration load}

A critical part of the refrigeration system model is the accurate prediction of the load of the refrigeration system at part load conditions from the specification of the design cooling load. At a steady state, the total cooling load of a display cabinet $Q_{\text {case }}$ arises from wall heat conduction $Q_{\text {wall }}$, radiation $Q_{\text {rad }}$, cabinet lights $Q_{\text {light }}$, evaporator fan $Q_{\text {evfan }}$, sensible part of infiltration $Q_{i n f, s e n}$, latent part of infiltration $Q_{\text {inf,lat }}$, anti-sweet heater $Q_{a s w}$ and defrost $Q_{d e f}$.

$$
Q_{\text {case }}=Q_{\text {wall }}+Q_{\text {rad }}+Q_{\text {light }}+Q_{\text {evfan }}+Q_{\text {inf }, \text { sen }}+Q_{\text {inf }, \text { lat }}+Q_{a s w}+Q_{\text {def }}
$$


On the right hand side of equation (1), the first five terms are not affected by internal space air humidity unlike the last three terms. When the space air temperature is controlled at a constant value, the first five terms no longer change during a partload condition while the last three items vary with space air humidity. To account for this, correlation coefficients are developed which relate the sensible infiltration, latent infiltration, anti-sweat heater and defrost loads at a specific time interval and indoor relative humidity to the load at an indoor relative humidity of $55 \%$. The four respective terms $R_{T}, R_{L}, R_{A}$ and $R_{D}$ are defined as follows:

$$
\begin{aligned}
& R_{T}=\frac{Q_{\text {inf, tot }}}{Q_{\text {inf }, \text { tot }, r}} \\
& R_{L}=\frac{Q_{\text {inf, lat }}}{Q_{\text {inf }, \text { lat }, r}} \\
& R_{A}=\frac{Q_{\text {asw }}}{Q_{\text {asw }, r}} \\
& R_{D}=\frac{Q_{\text {def }}}{Q_{\text {def }, r}}
\end{aligned}
$$

Howell et al $(1991,1993)$ have shown that these ratios have a linear relationship with space humidity such as:

$$
R_{T}, R_{L} \text { or } R_{D}=A \times R H_{s p}+B
$$

The constant coefficients $\mathrm{A}$ and $\mathrm{B}$ in equation (6) for each ratio and cabinet type have been calculated and are listed in Table 1. 
The ratio $R_{A}$ can be related to the space air dew point temperature and cabinet temperature as follows (Howell and Adams, 1991; Howell, 1993).

$$
R_{A}=\frac{T_{d e w}-T_{\text {case }}}{T_{\text {dew }, r}-T_{\text {case }}}
$$

At design conditions, the percentage load distribution for different types of display cabinets used in the model are based on the results of Walker et al (Walker et al., 2004), shown in Fig. 6. From these and the design cooling loads of the cabinets taken from manufacturers' data the individual loads of the cabinets at design and part-load conditions can be determined.

Table 2 shows the design loads of the refrigeration fixtures served by the HT pack and Tables 3 and 4 show the design loads for the refrigeration fixtures served by LT1 and LT2 packs respectively.

\subsubsection{Compressor model}

The compressor types used in supermarket refrigeration systems are mostly semihermetic reciprocating and scroll. For simplicity and reasonable degree of accuracy, the map-based compressor model is utilized (Fischer and Rice, 1983). The map-based routine uses performance curve fits for the compressor power consumption and cooling capacity as functions of saturated suction temperature $\left(t_{s s}\right)$ and saturated discharge temperature $\left(t_{s d}\right)$ :

$$
W_{c p}\left(\text { or } Q_{c p}\right)=c_{1} \times t_{s d}^{2}+c_{2} \times t_{s d}+c_{3} \times t_{s s}^{2}+c_{4} \times t_{s s}+c_{5} \times t_{s s} \times t_{s d}+c_{6}
$$

If a compressor works in the transcritical cycle with $\mathrm{CO}_{2}$ refrigerant, a modified equation is employed for the calculation of the compressor power consumption: 
$W_{c p}=c_{1} \times p_{h p}^{2}+c_{2} \times p_{h p}+c_{3} \times t_{s s}^{2}+c_{4} \times t_{s s}+c_{5} \times t_{s s} \times p_{h p}+c_{6}$

The cooling capacity of a $\mathrm{CO}_{2}$ compressor in the transcritical cycle can be calculated from:

$Q_{c p}=c_{1} \times h_{g o}^{2}+c_{2} \times h_{g o}+c_{3} \times t_{s s}^{2}+c_{4} \times t_{s s}+c_{5} \times t_{s s} \times h_{g o}+c_{6}$

It should be noted that coefficients $\mathrm{c}_{1} \sim \mathrm{c}_{6}$ can be determined from performance curve fits of manufacturers' data for compressor power consumption and cooling capacity.

\subsubsection{Condenser model}

To predict the total fan power consumption of the air cooled condensers and actual head pressure in the system at part-load conditions, a simplified condenser model combined with fan power calculation has been utilised (Chan and $\mathrm{Yu}, 2004)$. When the geometric characteristics and fan particulars of a particular condenser are known and computational time is not an important consideration in the simulations, a detailed condenser model can also be employed to evaluate the effect of heat exchanger design parameters on system performance (Ge and Cropper, 2004).

When refrigerant properties (temperature and pressure) at condenser inlet and outlet, refrigerant mass flow rate and ambient air temperature are available at steady state, the simplified model is able to predict the required air flow rate, number of fans operating and total fan power consumption using the following equations(Chan and Yu, 2004):

$$
Q_{c d}=m_{r}\left(h_{\text {rin }}-h_{\text {rout }}\right)=V_{a} \times \rho_{a} \times C_{p a}\left(T_{\text {aout }}-T_{\text {ain }}\right)
$$




$$
\begin{aligned}
& T_{a o u t}=\frac{Q_{c d}}{V_{a} \times \rho_{a} \times C_{p a}}+T_{a i n}<T_{r c d} \\
& \frac{Q_{c d}}{\rho_{a} \times C_{p a}\left(T_{r c d}-T_{a i n}\right)}<V_{a} \\
& V_{a}=\frac{N_{f a n, p l}}{N_{f a n, f l}} \times V_{a, f l}
\end{aligned}
$$

The minimum operational fan number at part load conditions can be calculated from:

$$
N_{f a n, m i n}=\frac{N_{f a n, f l}}{V_{a, f l} \times \rho_{a} \times C_{p a}} \times \frac{Q_{c d}}{\left(T_{r c d}-T_{a i n}\right)}
$$

The actual total condenser fan power consumption can then be determined:

$$
W_{f a n, t o t}=N_{f a n, m i n} \times W_{o n e f a n, r}
$$

The model requires specification of the steady state fan power consumption in relation to the compressor pack cooling load. For the compressor packs used in the supermarket under consideration the steady state fan power was assumed to be $5.3 \%$ and $10.0 \%$ of the rated cooling load for the HT and LT packs respectively, based on results from field measurements (Walker and Baxter, 2001). If the full-load operation state is specified, the full-load air volumetric flow rate $V_{a, f l}$ can be calculated from equation (13). In this study, 6 condenser fans are used for each temperature pack which are switched on and off in stages according to the load and head (condenser) pressure control strategy. At higher ambient temperatures the condenser, even when all the fans are running, may have insufficient capacity to maintain the head pressure 
at the set value. In these conditions the head pressure will rise above the control set point. It is noted that the condenser model can also be applied to the prediction of fan power consumption when motor frequency control is utilised. In such a case, the ratio of fan numbers at part and full loads is replaced with corresponding motor frequencies in equation (14).

\section{MODEL VALIDATION AND SIMULATION RESULTS}

The refrigeration systems for the supermarket considered employed R22 as a refrigerant. The control strategy used a fixed head pressure control at 15 bar for each pack, achieved by switching the condenser fans on and off, and a constant suction pressure control set at 3.3 bar for the HT pack and 1.38 bar for the LT packs, achieved by switching the compressors on the packs on and off in response to the variation in load.

Field data were used to validate the simulation model developed. Fig. 7 shows a comparison between the simulation and actual variation of space relative humidity over a 12 month period.

It can be seen that the indoor relative humidity rises in the summer months and drops in the winter months. This is mainly due to the increased ventilation rates in the summer months which counteract the dehumidification that takes place in the evaporator coils of the refrigerated display cabinets. The model predicts reasonably well the seasonal variation in relative humidity. The greatest deviation is in the summer months where the impact of the outdoor ventilation and infiltration air is greatest.

With the indoor space temperature controlled at a constant value, the variation of relative humidity has an influence on the cooling load of the refrigeration system as 
does the variation of the outdoor temperature. The variation of the daily refrigeration load of the three compressor packs predicted by the model is shown in Fig. 8. It can be seen that, the load rises in the summer and reduces in the winter due to the higher outdoor ambient temperature and higher indoor relative humidity in the summer months. For instance, in summer period between June and September, the cooling load of HT pack is about $15 \%$ higher than that in winter period from January to April. Controlling the indoor relative humidity in the summer months should lead to energy savings and this area needs further investigation.

The variation in the refrigeration load determines the number of operational compressors, and consequently the compressor power and daily electrical energy consumption of the compressor packs, as shown in Fig. 9. The Figure also shows a comparison between the simulation results and actual energy consumption of the high temperature pack (HT). It can be seen that the simulation model predicts the variation of the electrical energy consumption of the packs reasonably well. Table 5 shows a comparison of the simulated and actual seasonal electrical energy consumption of the packs. The maximum error is $-8.1 \%$ for LT pack 2 , whilst the minimum error is $2.7 \%$ for the HT pack.

Since the refrigerant head pressure control was set to 15 bar for each temperature pack which was less than the designed value (19.43 bar, $50{ }^{\circ} \mathrm{C}$ condensing temperature), the actual head pressure may deviate from the controlled value at high ambient air temperatures even less than the designed $35{ }^{\circ} \mathrm{C}$ when the condenser capacity is unable to cope with the increased refrigeration load. The variation of the head (condensing) pressure with ambient temperature for the HT and LT packs and the corresponding variation of the compressor pack power consumption for a warm summer day are shown in Fig. 10. Since the predicted head pressure of the LT packs is very similar only the LT1 pack is shown in the Figure. 
It can be seen that for most of the day, up to around 12.00 p.m. when the ambient temperature is below $28{ }^{\circ} \mathrm{C}$ the discharge pressure of the HT pack is controlled at the set value. As the temperature rises above $28{ }^{\circ} \mathrm{C}$, the discharge pressure also rises followed by a rise in the compressor power, reaching maximum at around 2.00 p.m. when the ambient temperature is around $32.0{ }^{\circ} \mathrm{C}$ before dropping down within the controlled range at around 4.00 p.m. The $4.0{ }^{\circ} \mathrm{C}$ in the ambient temperature leads to a 2.2 bar rise in the head pressure which in turn causes in excess of $30 \%$ rise in the power consumption of the HT pack. A similar behaviour can be observed for the LT pack.

Fig. 11 shows the variation of the outdoor temperature during the year. It can be seen that the outdoor temperature in the location of the supermarket exceeds $28{ }^{\circ} \mathrm{C}$ only for a few hours in the year so the selection of the design temperature for the sizing of the equipment will be a compromise between the energy consumption of the compressors and the size of the condensers and energy consumption of the condenser fans which are cycled on and off to control the head pressure to the design value. Fig. 12 shows the daily variation of the electrical energy consumption of the condenser fans serving the three compressor packs in the supermarket. It can be seen that the energy consumption of the fans follows the variation of the outdoor temperature but it is still much lower than the energy consumption of the compressors ( Fig. 9).

Fig. 13 shows the variation of the space heating load of the supermarket and the heat available through heat recovery from the HT pack. It can be seen that the space heating load is maximum in the winter $(180 \mathrm{~kW})$ and reduces in the summer to a minimum of around $30 \mathrm{~kW}$. With fixed head pressure control it can be seen that the heat available from the HT pack is almost constant throughout the year at around 50 $\mathrm{kW}$. The percentage of space heating load that can be covered by heat recovery from the HT pack is shown in Fig. 14. It can be seen that heat recovery can be around $30 \%$ 
of the space heating load in the winter months and $100 \%$ of the load in the summer. Heat recovery, however, necessitates operation of the refrigeration equipment at high head pressures which increases the compressor power consumption. The economic viability of heat recovery from refrigeration equipment should be investigated carefully before it can be applied to a supermarket particularly when R22 or R404A are used as refrigerants (Arias and Lundqvist, 2006).

\section{CONCLUSIONS}

The supermarket system model "SuperSim" integrates refrigeration, building and HVAC models to investigate the interactions between these systems and determine the energy consumption of the supermarket. The model is able to carry out hourly system simulations and can be used to investigate the influence of component design and control on the overall system energy consumption. The model was validated against data from a fully instrumented supermarket and was found to predict the energy consumption of the refrigeration packs in the supermarket with a reasonable accuracy. The application of the model was demonstrated by considering the potential of heat recovery and the impact of outdoor ambient conditions on refrigeration system energy consumption.

Part II of this paper will consider further application of the model by simulating and comparing the energy performance of a conventional R404A system with a $\mathrm{CO}_{2}$ booster system in the supermarket.

\section{Acknowledgements:}


Work presented in this paper was carried out with financial support from the Department of Environment, Food and Rural Affairs (Defra). The authors would like to acknowledge the support of Defra and the input from the collaborating partners.

\section{References}

Arias,J., 2004. Cybermart Beta-version, KTH Sweden.

Arias J., Lundqvist P., 2006. Heat recovery and floating condensing in supermarkets. Energy and Buildings $38,73-81$.

Chan, K.T., Yu, F.W., 2004. Optimum setpoint of condensing temperature for aircooled chillers. HVAC\&R Research 10, n2, 113-127.

Dokka, T., H., 2001. Manual of Software SCIAQ Professional.

Econu Koeling V2 teat version, 2004. Sietze M. van der Sluis(TNO) and Henk Stijnen (DWA) for NOVEM and CBL, The Netherlands. August.

EnergyPlus, 2009. A model for heating, cooling, lighting, ventilating, and other energy flows as well as water in buildings. EnergyPlus Version 4.0.0.

Fischer, S.K., Rice, C.K.,1983. The Oak Ridge heat pump models: 1. a steady-state computer design model for air-to-air heat pumps, ORNL/CON-80/R1. August.

Ge, Y.T. , Cropper, R., 2004. Air-cooled condensers in retail systems using R22 and R404A refrigerants. Applied Energy 78, 95-110.

Ge, Y.T., Tassou, S.A., 2000. Mathematical Modelling of Supermarket Refrigeration System for Design, Energy Prediction and Control. Journal of Power and Energy, Proceedings of IMechE, Part A. 214, 101-114.

Howell, R. H. , Adams, P., 1991. Effects of indoor space conditions on refrigerated display case performance- Final Report for ASHRAE Project No. 596RP, 130pg.

Howell, R.H., 1993. Calculation of humidity effects on energy requirements of refrigerated display cases. ASHRAE Transactions, 679-693. 
RETScreen, 2009. international clean energy project analysis software.

Tassou S.A., 2007. Potential for Solar Energy in Food Manufacturing, Distribution and Retail, Report to DEFRA, AC045, 25 pgs.

Tassou, S.A., Ge, Y.T.,2008. Reduction of refrigeration energy consumption and environmental impacts in food retailing, In improving water and energy management in food processing. , Edited by J Klemeš, R Smith and J-K Kim, Woodhead Publishing, Chapter 20, 585-610., ISBN 1845691954.

The ORNL Supermarket spreadsheets, 2003. Steven Fischer, Oax Ridge National Laboratory. CD ROM distributed during the $21^{\text {st }}$ International Congress of Refrigeration, Washington DC USA, August 17-22.

TRNSYS,2005. A transient system simulation program, TRNSYS 16.

van der Sluis, S.M., 2004. Review of calculation programs for supermarket DX refrigerating systems year-round energy consumption. IIR/IIF D1-subcommission “Refrigerated Display Cabinets", Glasgow(UK) Meeting, August $31^{\text {st }}$.

Walker, D.H., Faramarzi, R.T., Baxter, V.D,2004. Investigation of energy-efficient supermarket display cases. Project report, ORNL/TM-2004/292. December.

Walker, D.H., Baxter, V.D., 2001, Development and demonstration of an advanced supermarket refrigeration/HVAC system . Project report, ORL-SX363X-FM97163-1231. September . 


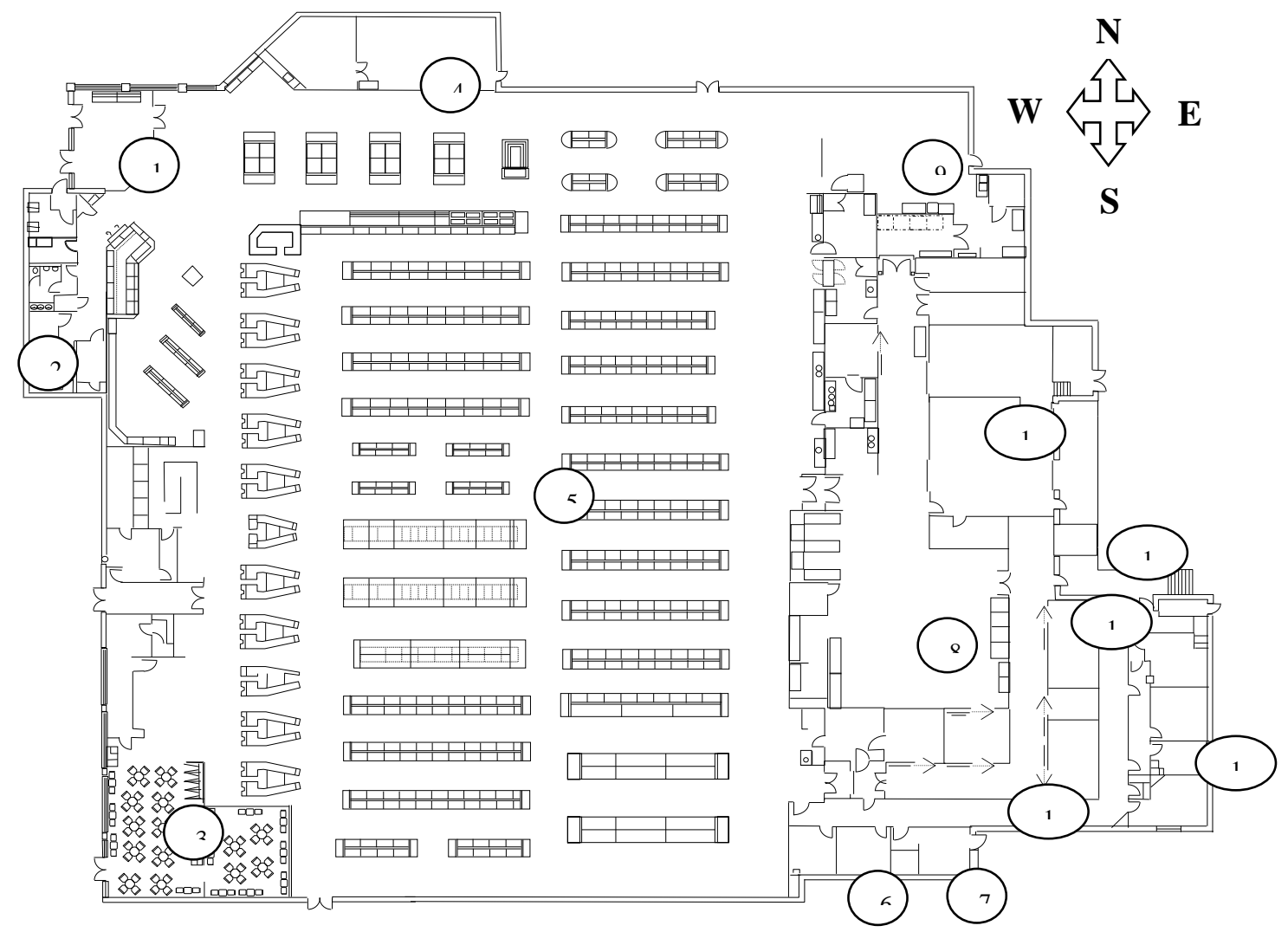

1-entry hall; 2 -rest rooms; 3-coffee area; 4-dry prep; 5-sale area; 6-staff room 1; 7staff stairs ; 8-cold rooms;9-bakery;10-corrioor; 11-gas room; 12-staff room 2; 13computer rooms; 14 -recieveing area

Fig. 1- Floor diagram of supermarket building with zone classification. 


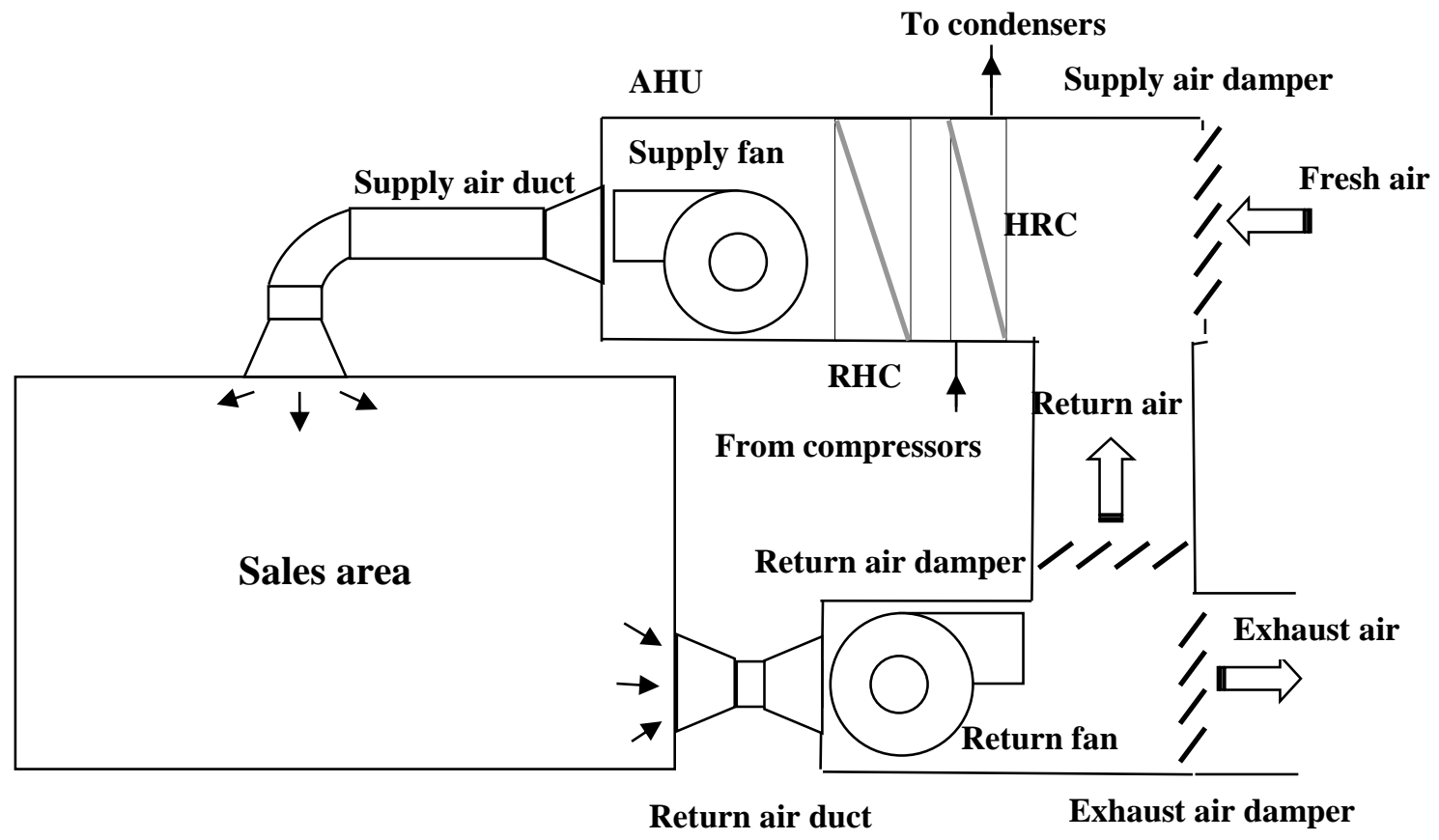

Fig. 2- Layout of HVAC system and heat reclaim coil connected with refrigeration system. 


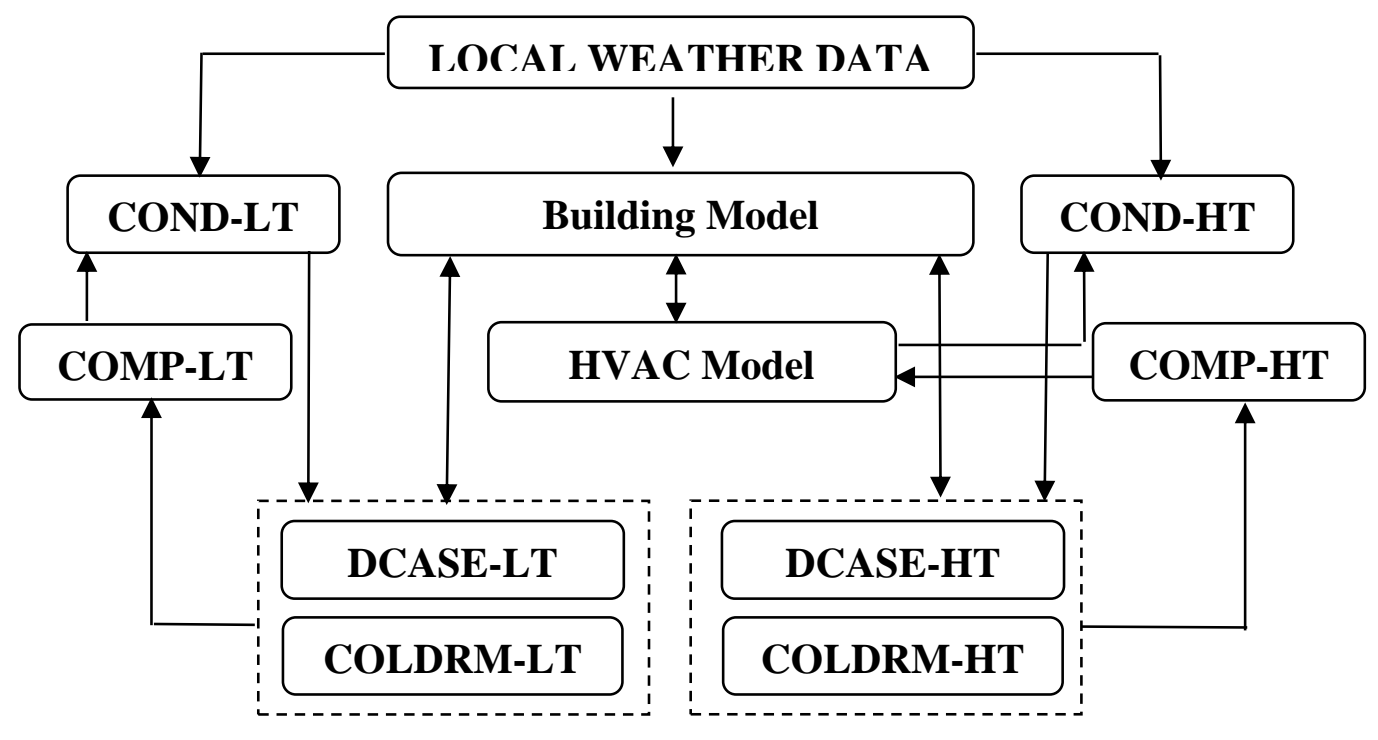

Fig. 3- Integration of major sub-system models 


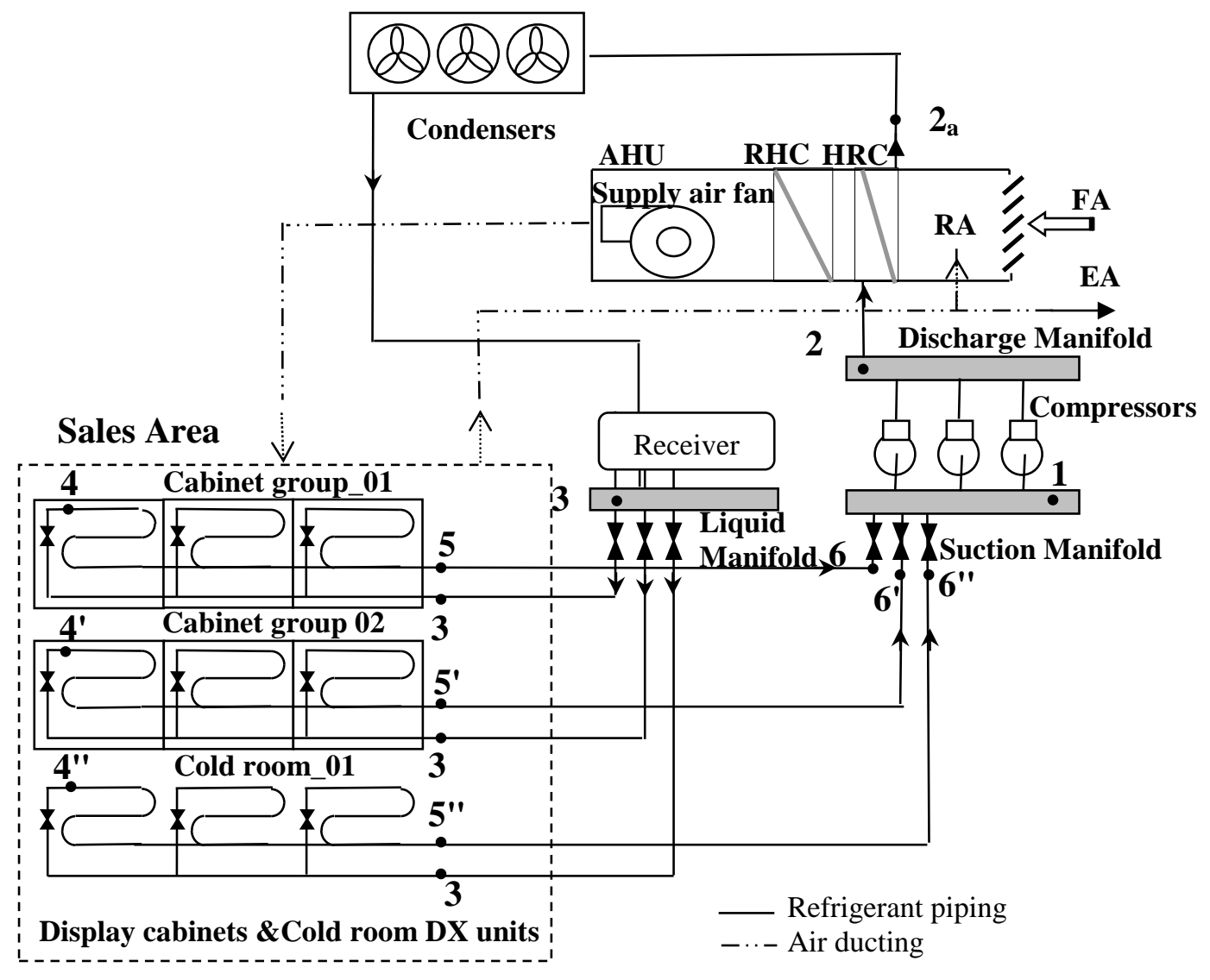

Fig. 4- Layout of HT pack refrigeration system and its interactions with HVAC system and building in supermarket 


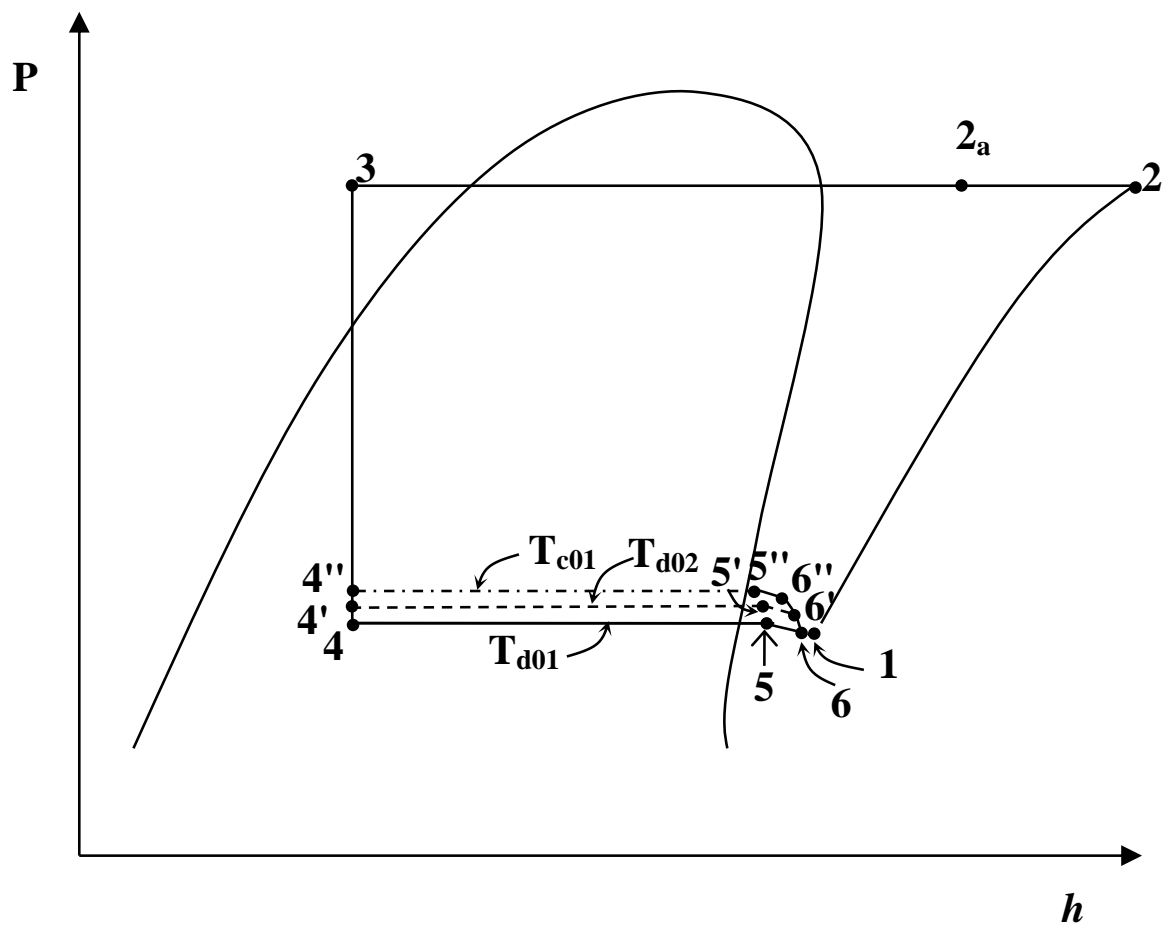

Fig. 5- Refrigeration cycle of the high-temperature pack circuit in the supermarket. 


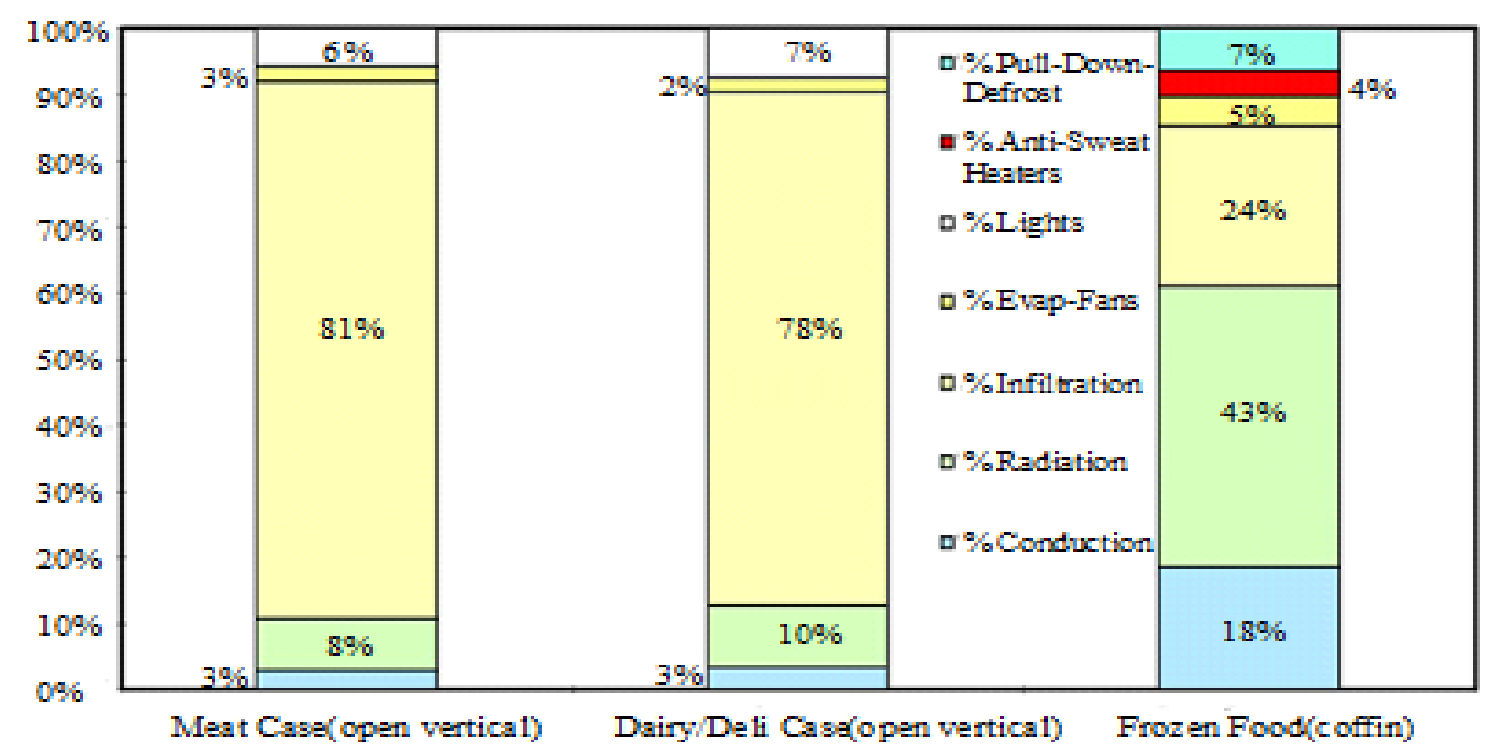

Fig. 6- Load distribution in some typical display cabinets 


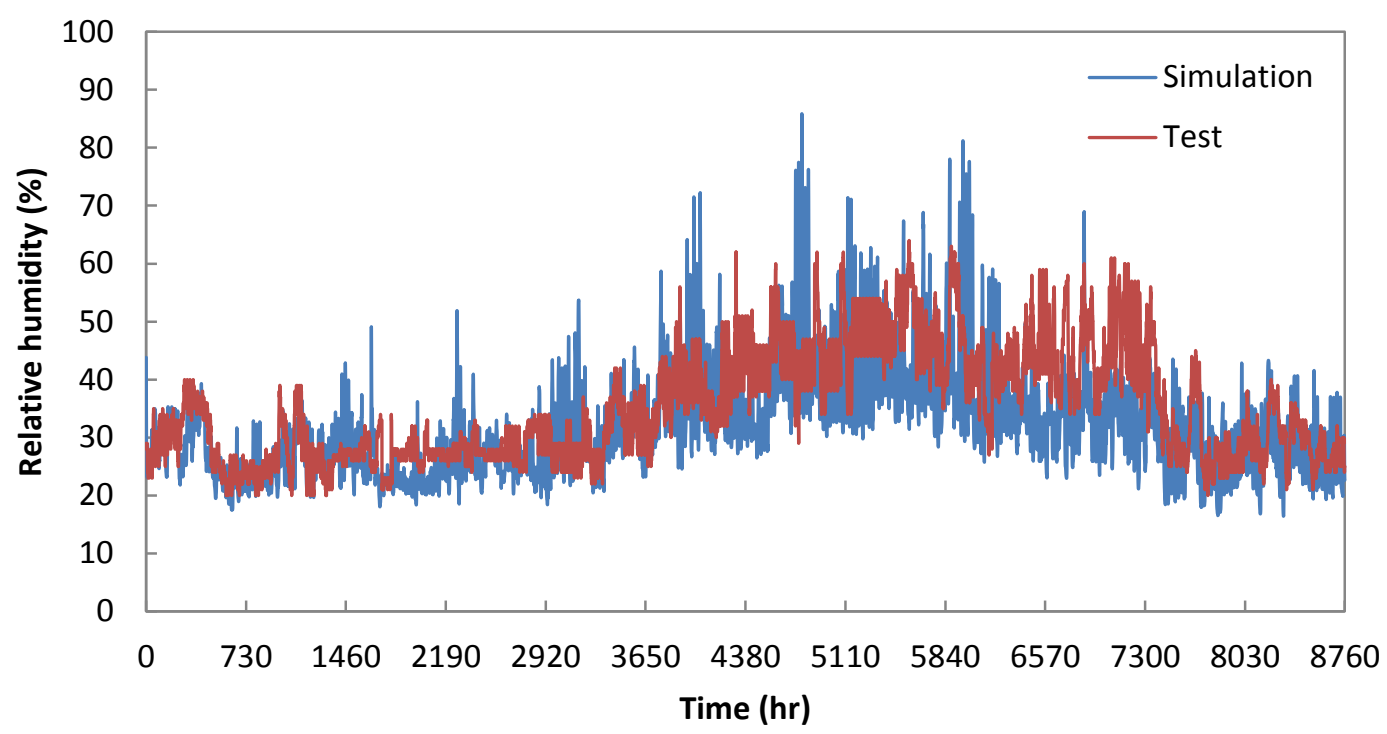

Fig. 7- Comparison of simulation and test results for hourly variation of space relative humidity. 


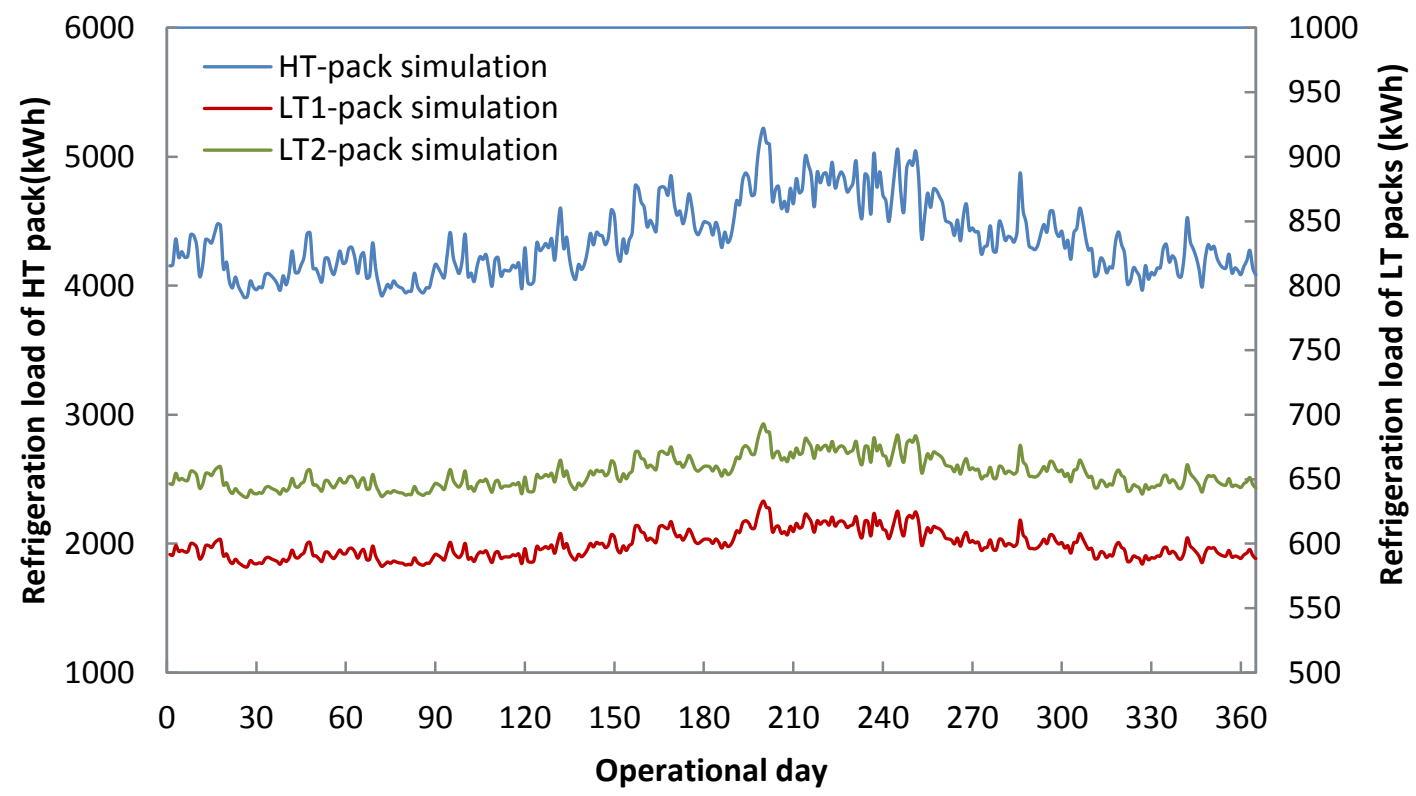

Fig. 8- Daily variation of compressor refrigeration load of HT and LT packs 


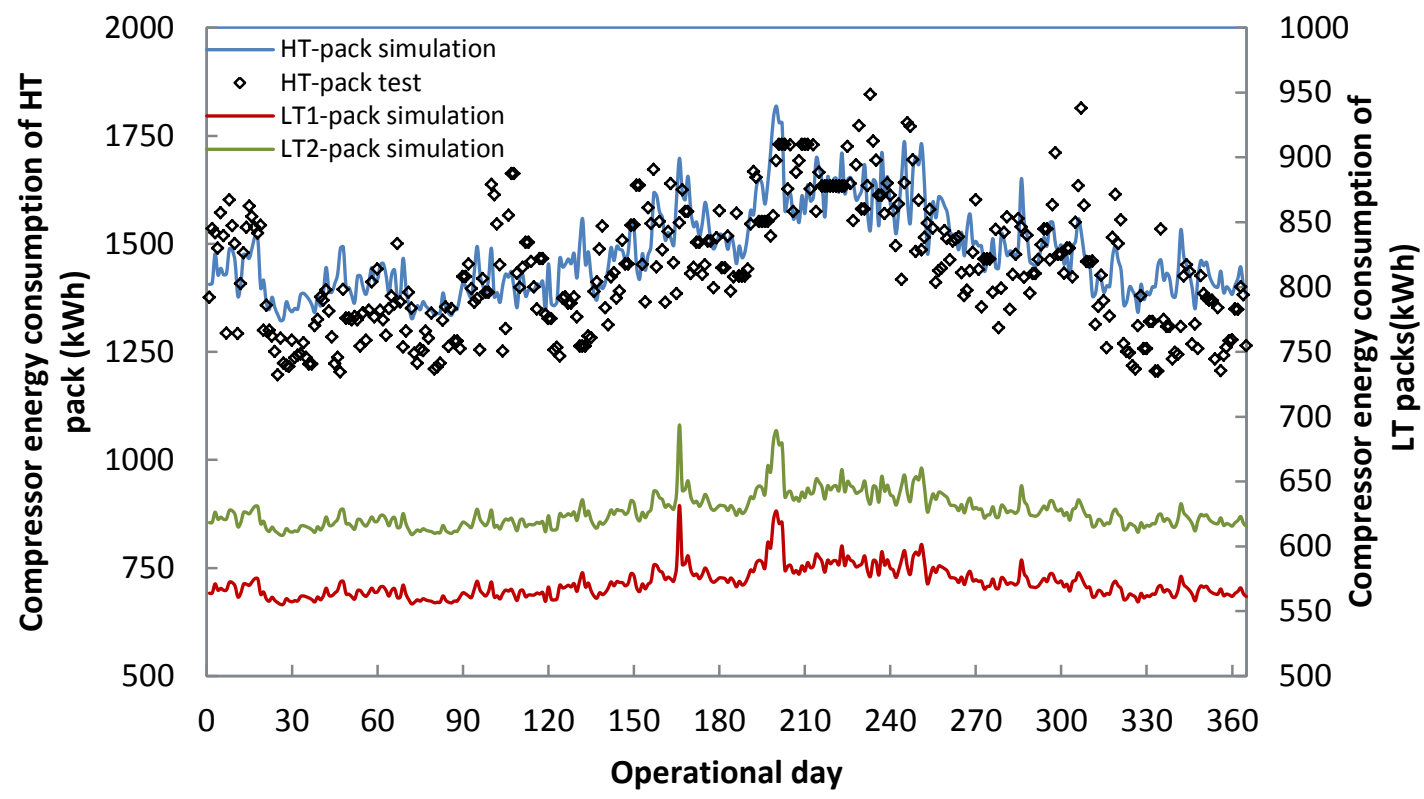

Fig. 9- Daily variation of HT and LT compressor energy consumption 


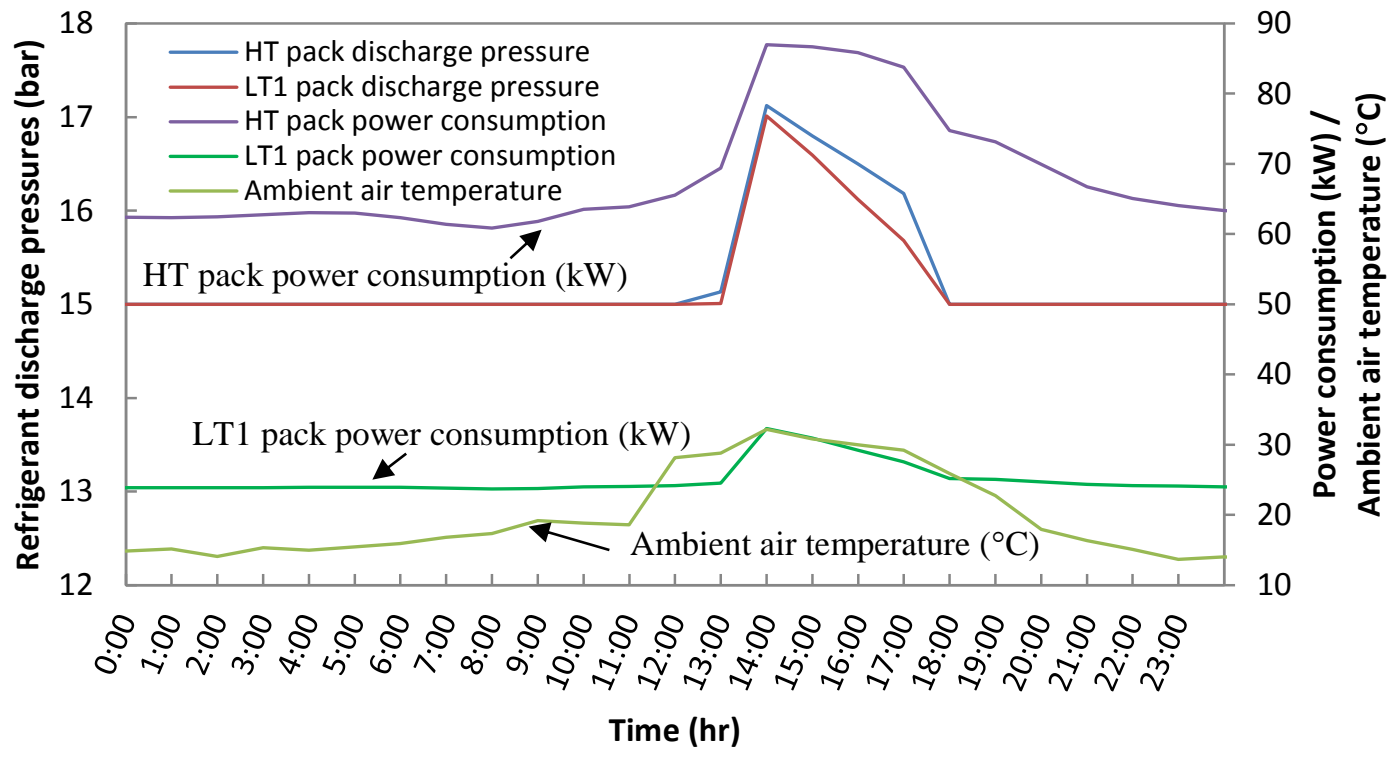

Fig. 10- Hourly variations of controlled refrigerant head pressures for HT and LT1 packs during one typical summer day. 


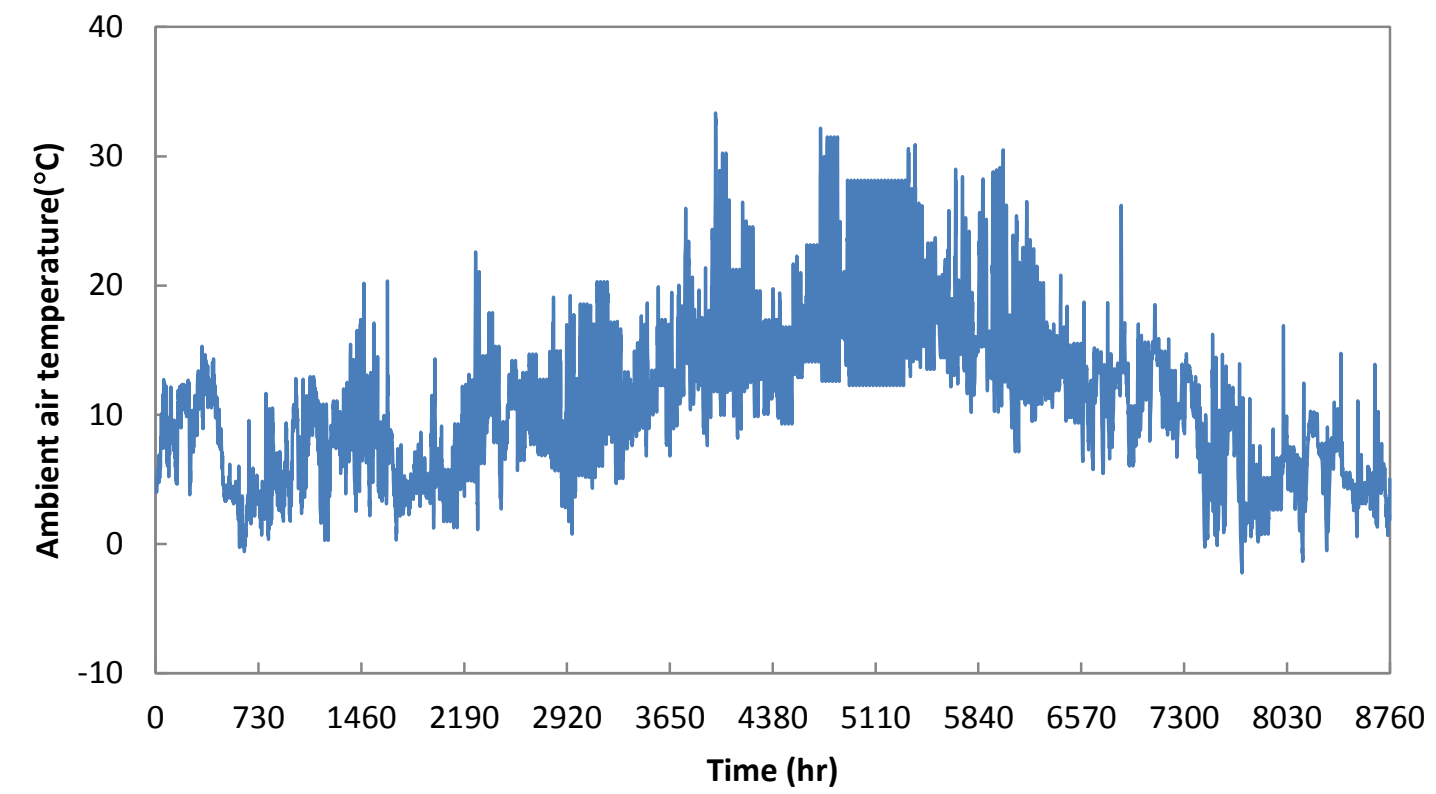

Fig. 11- Hourly variation of the outdoor temperature during the year of the simulations. 


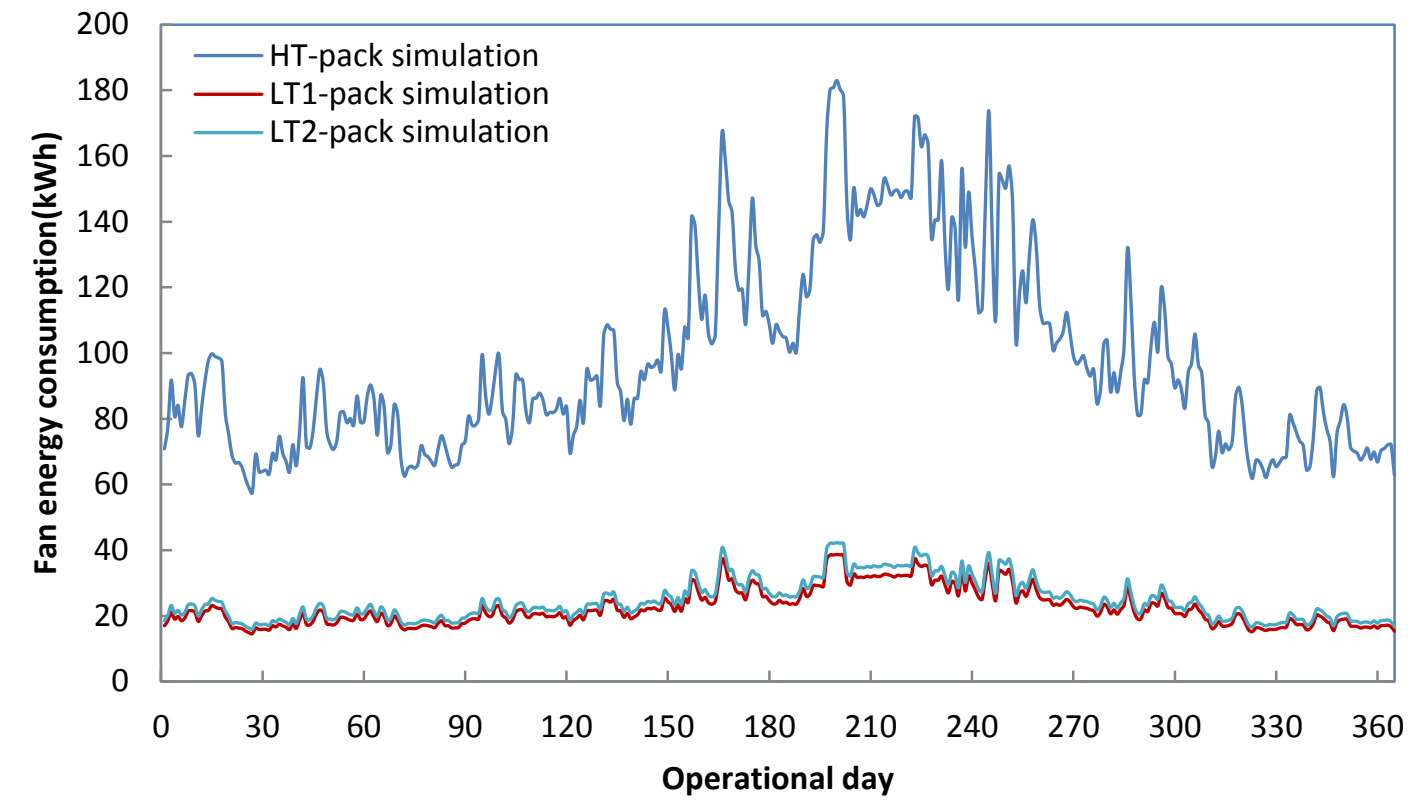

Fig. 12- Daily variations of the condenser fan energy consumption in each temperature pack during one year period. 


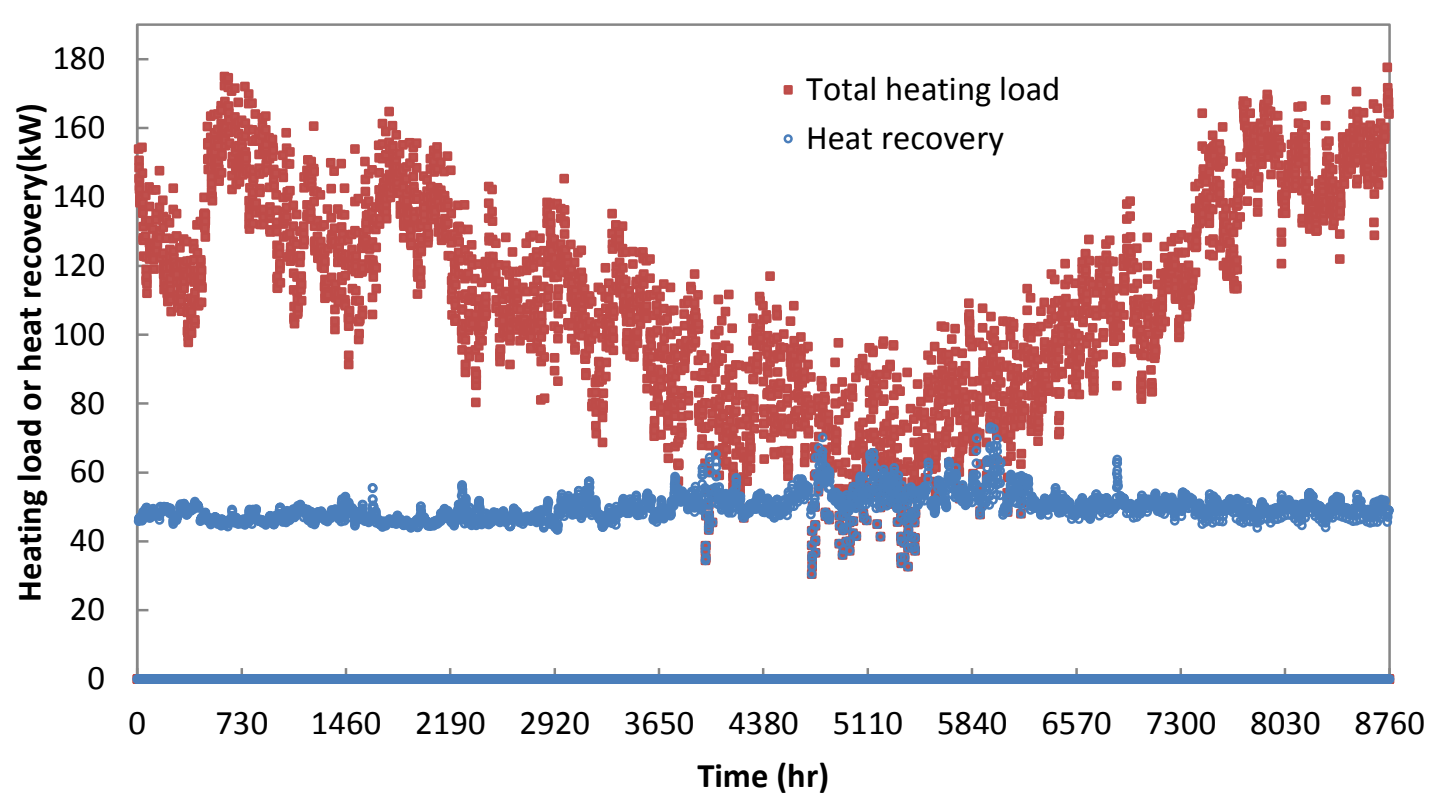

Fig. 13- Hourly variations of total heating load and heat recovery from AHU during one year period. 


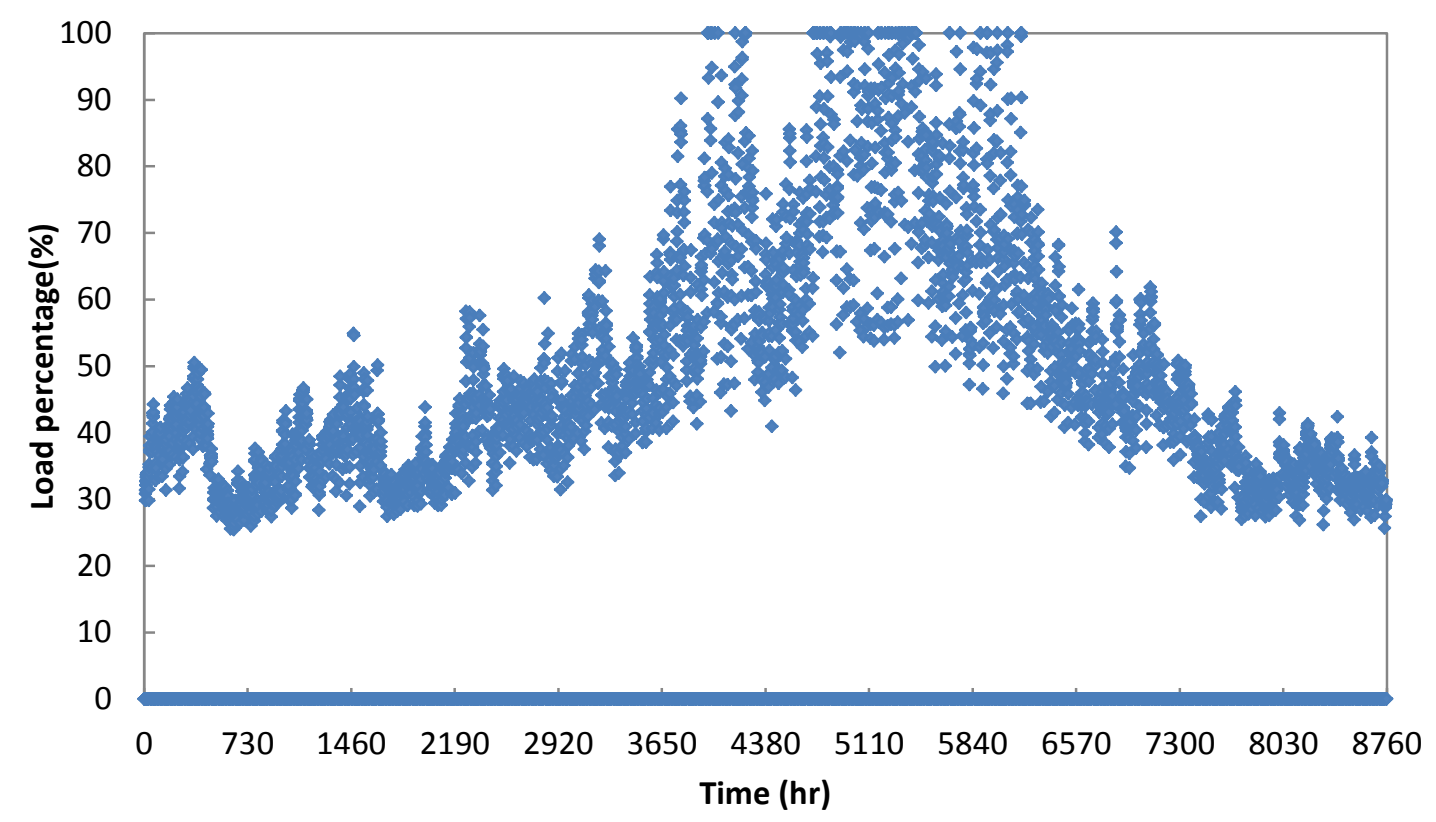

Fig. 14- Percentage heat recovery to total supermarket space heating load 
Table 1- Coefficients A and B for different cabinet types

\begin{tabular}{|c|c|c|c|c|c|c|}
\hline \multirow[t]{2}{*}{ Cabinet type } & \multicolumn{2}{|c|}{$\mathrm{R}_{\mathrm{T}}$} & \multicolumn{2}{|c|}{$\mathrm{R}_{\mathrm{L}}$} & \multicolumn{2}{|c|}{$R_{D}$} \\
\hline & A & B & A & B & A & B \\
\hline Single shelf meat & 0.0085 & 0.5334 & 0.0201 & -0.0996 & 0.0227 & -0.243 \\
\hline Multi shelf meat & 0.0107 & 0.4117 & 0.025 & -0.3738 & 0.0234 & -0.2855 \\
\hline Multi shelf dairy & 0.0141 & 0.2229 & 0.0334 & -0.8345 & 0.0297 & -0.6328 \\
\hline Multi shelf deli & 0.0127 & 0.3025 & 0.0297 & -0.6315 & 0.0272 & -0.4965 \\
\hline Single shelf produce & 0.0096 & 0.4736 & 0.0216 & -0.1833 & 0.027 & -0.4793 \\
\hline Multi shelf produce & 0.0142 & 0.22 & 0.0333 & -0.8307 & 0.0285 & -0.565 \\
\hline Single shelf Frozen Food & 0.0062 & 0.6595 & 0.0186 & -0.0179 & 0.019 & -0.0384 \\
\hline Single shelf ice cream & 0.0058 & 0.6817 & 0.0185 & -0.0134 & 0.0187 & -0.0257 \\
\hline Multi shelf frozen food & 0.0069 & 0.622 & 0.019 & -0.0473 & 0.0187 & -0.027 \\
\hline Glass Door Reach in-frozen food & 0.0074 & 0.591 & 0.0196 & -0.0785 & 0.0193 & -0.0592 \\
\hline Glass Door Reach in-ice cream & 0.007 & 0.6145 & 0.0192 & -0.0564 & 0.019 & -0.0427 \\
\hline
\end{tabular}


Table 2- Manufactures' data for display cabinets and cold rooms served by the hightemperature pack

\begin{tabular}{|c|c|c|c|c|c|}
\hline HT-pack & STUB No. & Cabinet / Coldroom & $\begin{array}{c}\text { Evap. Temp. } \\
{ }^{\circ} \mathrm{C}\end{array}$ & Display Temp. ${ }^{\circ} \mathrm{C}$ & $\begin{array}{c}\text { Extraction Rate } \\
\qquad \mathrm{kW}\end{array}$ \\
\hline \multirow{17}{*}{ Dcase } & 1 & Fresh Meat & -10 & $-2 /+2$ & 16.32 \\
\hline & 2 & Fresh Meat & -10 & $-2 /+2$ & 12.70 \\
\hline & 3 & Fresh Meat/Dairy & -10 & $-2 /+2$ & 14.32 \\
\hline & 4 & Dairy & -8 & $0 /+3$ & 8.60 \\
\hline & 5 & Dairy & -8 & $0 /+3$ & 12.04 \\
\hline & 6 & Dairy & -8 & $0 /+3$ & 13.76 \\
\hline & 7 & Dairy & -8 & $0 /+3$ & 8.60 \\
\hline & 8 & Dairy & -8 & $0 /+3$ & 13.76 \\
\hline & 9 & Dairy/Roll-In Dairy & -8 & $0 /+3$ & 13.20 \\
\hline & 10 & Meat & -10 & $-2 /+2$ & 12.70 \\
\hline & 11 & Meat & -10 & $-2 /+2$ & 10.88 \\
\hline & 12 & Delicatessen & -10 & $0 /+2$ & 5.07 \\
\hline & 13 & S.S. Cakes/Produce & -8 & $0 /+2$ & 8.08 \\
\hline & 14 & Produce & -8 & $0 /+2$ & 12.60 \\
\hline & 15 & Produce & -10 & $0 /+2$ & 7.13 \\
\hline & 16 & Serve-Over Meat & -6 & $0 /+2$ & 0.96 \\
\hline & 17 & Dairy & -8 & $0 /+5$ & 3.44 \\
\hline \multirow{10}{*}{ Coldrm } & 1 & Restaurant Counter & -10 & $0 /+2$ & 1.87 \\
\hline & 2 & Holding Area & +4 & +10 & 17.58 \\
\hline & 3 & Meat Chiller & -7 & $-1 /+1$ & 3.20 \\
\hline & 4 & Produce Chiller & -3 & $+3 /+5$ & 3.52 \\
\hline & 5 & Dairy Chiller & -6 & $0 /+2$ & 3.66 \\
\hline & 6 & Delicatessen Prep & +4 & +10 & 3.00 \\
\hline & 7 & Delicatessen Chiller & -6 & $0 /+2$ & 2.68 \\
\hline & 8 & Bakery Chiller & -3 & $+3 /+5$ & 0.56 \\
\hline & 9 & Dough Retarder & -10 & - & 5.30 \\
\hline & 10 & Meat Prep & +4 & $4 / 6$ & 5.00 \\
\hline
\end{tabular}


Table 3- Manufacturers' data for display cabinets and cold rooms served by LT pack 1.

\begin{tabular}{|c|c|c|c|c|c|}
\hline LT-pack1 & STUB No. & Cabinet / Coldroom & $\begin{array}{l}\text { Evap. Temp. } \\
{ }^{\circ} \mathrm{C}\end{array}$ & Display Temp. ${ }^{\circ} \mathrm{C}$ & $\begin{array}{l}\text { Extraction Rate } \\
\text { kW }\end{array}$ \\
\hline \multirow{8}{*}{ Dcase } & 1 & Ice-Cream (Well) & -38 & $-26 /-24$ & 3.07 \\
\hline & 2 & Ice-Cream (Well) & -38 & $-26 /-24$ & 2.56 \\
\hline & 3 & Frozen Food (Door) & -32 & $-20 /-18$ & 3.31 \\
\hline & 4 & Frozen Food (Well) & -32 & $-20 /-18$ & 3.08 \\
\hline & 5 & Frozen Food (Door) & -32 & $-20 /-18$ & 2.48 \\
\hline & 6 & Frozen Food (Well) & -32 & $-20 /-18$ & 3.08 \\
\hline & 7 & Frozen Food (Door) & -32 & $-20 /-18$ & 2.52 \\
\hline & 8 & Frozen Food (Well) & -32 & $-20 /-18$ & 1.66 \\
\hline Coldrm & 1 & Frozen Food & -26 & $-16 /-18$ & 4.40 \\
\hline
\end{tabular}


Table 4- Manufacturers' data for display cabinets and cold rooms served by LT pack 2.

\begin{tabular}{|c|c|c|c|c|c|}
\hline LT-pack2 & STUB No. & Cabinet / Coldroom & $\begin{array}{c}\text { Evap. Temp. } \\
{ }^{\circ} \mathrm{C}\end{array}$ & Display Temp. ${ }^{\circ} \mathrm{C}$ & $\begin{array}{c}\text { Extraction Rate } \\
\qquad \mathrm{kW}\end{array}$ \\
\hline \multirow{8}{*}{ Dcase } & 1 & Ice-Cream (Door) & -38 & $-26 /-24$ & 4.05 \\
\hline & 2 & Ice-Cream (Door) & -38 & $-26 /-24$ & 3.37 \\
\hline & 3 & Frozen Food (Well) & -32 & $-20 /-18$ & 3.08 \\
\hline & 4 & Frozen Food (Well) & -32 & $-20 /-18$ & 2.32 \\
\hline & 5 & Frozen Food (Door) & -32 & $-20 /-18$ & 3.31 \\
\hline & 6 & Frozen Food (Door) & -32 & $-20 /-18$ & 3.31 \\
\hline & 7 & Frozen Food (Door) & -32 & $-20 /-18$ & 1.66 \\
\hline & 8 & Frozen Food (Well) & -32 & $-20 /-18$ & 2.48 \\
\hline \multirow{2}{*}{ coldrm } & 1 & Ice-Cream & -34 & $-20 /-18$ & 2.82 \\
\hline & 2 & Bakery Freezer & -26 & $-20 /-18$ & 2.24 \\
\hline
\end{tabular}


Table 5- Comparison of predicted and actual seasonal electrical energy consumption of compressor packs

\begin{tabular}{cccc} 
Temperature pack & $\mathrm{W}_{\mathrm{cp}, \text { sim }}$ & $\mathrm{W}_{\mathrm{cp}, \text { test }}$ & Error \\
& $\mathrm{kWh}$ & $\mathrm{kWh}$ & $\%$ \\
\hline High & 539142 & 525147 & 2.7 \\
low-1 & 208616 & 215775 & -3.3 \\
low-2 & 228829 & 249014 & -8.1 \\
\hline
\end{tabular}

